\title{
Characteristics of Anodized Layer in Investment Cast Ni50Ti50 Shape Memory Alloy
}

\author{
Shimaa H. El-Hadad, ${ }^{1}$ Khaled M. Ibrahim, ${ }^{1}$ and Lothar Wagner ${ }^{2}$ \\ ${ }^{1}$ Central Metallurgical R\&D Institute (CMRDI), P.O. Box 87, Helwan, Cairo, Egypt \\ ${ }^{2}$ Institue of Materials Science and Engineering, TU Clausthal, Agricolastr. 6, 38678 Clausthal-Zellerfeld, Germany \\ Correspondence should be addressed to Shimaa H. El-Hadad; shimaam@yahoo.com
}

Received 27 December 2013; Accepted 6 January 2014; Published 25 February 2014

Academic Editor: Michael E. Kassner

Copyright (c) 2014 Shimaa H. El-Hadad et al. This is an open access article distributed under the Creative Commons Attribution License, which permits unrestricted use, distribution, and reproduction in any medium, provided the original work is properly cited.

NiTi shape memory alloys are promising implant materials due to their shape memory effect and super elasticity. In the current study, some Ni50Ti50 (mass \%) SMAs samples were prepared by investment casting. These samples were then anodized and thermally treated to improve the surface properties. A fully saturated oxide layer was obtained. The structure and hardness properties of the anodized surfaces were then investigated. A hard porous layer with no free $\mathrm{Ni}$ atoms could be obtained which can be used as prebiomimetic surface for biological application.

\section{Introduction}

NiTi shape memory alloys (SMAs) are promising materials to develop state-of-the-art devices in the medical and dental field. The pseudoelasticity and shape memory effect of these alloys give them unique properties over the wide range of the developed alloys $[1,2]$. In addition, NiTi possesses high corrosion resistance by virtue of a titanium oxide film naturally formed over its surface. Owing to these desirable thermomechanical properties and chemical stability, NiTi is becoming a popular biomaterial $[3,4]$. However, the high nickel content has hampered the wider applications of these materials. Excessive surface corrosion and wear of NiTi raise health concerns because $\mathrm{Ni}$ ions released to body tissues and fluids can induce toxic and allergic responses [5]. By choosing a suitable surface modification method [6], hardness and corrosion resistance as well as biocompatibility of NiTi shape memory alloy can be improved. Among these methods, those not involving a high temperature during treatment (preferably less than $300^{\circ} \mathrm{C}$ ) are particularly important because $\mathrm{NiTi}$ is very sensitive to heat treatment. Exposure of NiTi to a high temperature treatment may disrupt or remove the prescribed built-in properties [7].

Anodization is a common and simple low-temperature process employed for thickening the oxide film over the surface of Ti and its alloys. Sharma [8] showed unexpected differences between anodization of $\mathrm{NiTi}$ alloys and $\mathrm{Ti}$ alloys [9]. In order to further investigate anodization of $\mathrm{Ni}-\mathrm{Ti}$ alloy, surface anodization was applied in the current work. Characteristics, hardness, and corrosion of the thin film obtained by anodization were investigated.

\section{Experimental}

2.1. Samples Preparation. Ni-Ti alloy samples were prepared by using an investment casting technique. A double vacuum melting process was performed to ensure the quality, purity, and properties of the material. Ingots of Ni50Ti50 (mass $\%)$ were melted in a vacuum induction skull melting (ISM) furnace. The molten metal was then poured in a ceramic mold. Two cast bars with $30 \mathrm{~mm}$ diameter and $300 \mathrm{~mm}$ length were obtained and then machined to $(25 \mathrm{~mm} \times 250 \mathrm{~mm})$ bars. The samples were wire cut and then studied by using optical (OM) and scanning electron microscopies (SEM).

2.2. Anodization. Samples of $5 \mathrm{~mm}$ thickness were wire cut from the as-cast bars for the anodization purpose. The samples were then polished with $\mathrm{SiC}$ papers of different grades and finally with $0.1 \mu$ alumina paste. The polished 
TABLE 1: Chemical composition of Hank's physiological solution.

\begin{tabular}{lc}
\hline $\mathrm{NaCl}$ & $8 \mathrm{~g} / \mathrm{L}$ \\
$\mathrm{KCl}$ & $0.4 \mathrm{~g} / \mathrm{L}$ \\
$\mathrm{NaHCO}_{3}$ & $0.35 \mathrm{~g} / \mathrm{L}$ \\
$\mathrm{KH}_{2} \mathrm{PO}_{4}$ & $0.06 \mathrm{~g} / \mathrm{L}$ \\
$\mathrm{Na}_{2} \mathrm{HPO}_{4}$ & $0.0475 \mathrm{~g} / \mathrm{L}$ \\
$\mathrm{C}_{6} \mathrm{H}_{12} \mathrm{O}_{6}$ (glucose) & $1 \mathrm{~g} / \mathrm{L}$ \\
\hline
\end{tabular}

${ }^{*} 37^{\circ} \mathrm{C}$ : Hank's physiological solution buffered with HEPES (3.5745 g/L) at the normal physiological pH of 7.4.

samples were cleaned in acetone and then in deionized water before anodization. Anodization was carried out in a cell consisting of $\mathrm{NiTi}$ as the anode and stainless steel $316 \mathrm{~L}$ as cathode. A solution of $\left[1 \mathrm{M} \mathrm{H}_{2} \mathrm{SO}_{4}+0.15 \mathrm{wt} \% \mathrm{HF}\right]$ was used as electrolyte and kept at room temperature. The $\mathrm{NiTi}$ samples were anodized at $10 \mathrm{~V}$ for $1 \mathrm{~h}$ and then cleaned in deionized water. Some selected samples were chosen for carrying out hydrothermal treatment in water at $170^{\circ} \mathrm{C}$ for $18 \mathrm{~h}$. The surface morphology of the anodized and bare samples was studied using SEM. The surface compositions of the samples were acquired using X-ray diffraction of the $\mathrm{NiTi}$ thin film (TF-XRD) before and after anodization and thermal treatments.

2.3. Hardness Testing. The indentation method was usually adopted to test the hardness because of its unique simplicity and economy. A Vickers micro-hardness tester (cone) was employed to measure the hardness values of the deposited film at a normal load of $0.49 \mathrm{~N}$.

2.4. Corrosion Testing. The corrosion test was carried out in order to know the corrosion resistance of the sample before and after anodization. This test was done in three electrode cells. Potentiodynamic polarisation experiments were carried out in Hank's solution, whose composition is given in Table 1. $\mathrm{A} \mathrm{pH}$ of 7.4 and normal human body temperature of $37^{\circ} \mathrm{C}$ were maintained throughout the experiment. The procedures were conducted in accordance with ASTM standard G5-94 using PGSTAT30 potentiostat. The specimen, with an area of $1 \mathrm{~cm}^{2}$, was exposed to the Hank's solution for $5 \mathrm{~min}$ prior to potentiodynamic polarisation. A stable open circuit potential (OCP) was monitored. Saturated calomel electrode (SCE) was used as reference electrode. The recorded potentiodynamic polarization curves were used to obtain the characteristic parameters for corrosion behaviour, that is, corrosion current density $\left(I_{\text {corr }}\right)$ pitting potential $\left(E_{\text {pit }}\right)$ and corrosion rate. These parameters were typically determined by extrapolation of the Tafel lines of each polarization curve. The as-corroded surface of the samples was investigated using SEM and the corrosion products were also analyzed using energy dispersive spectroscopy (EDX).

\section{Results and Discussion}

3.1. Microstructure and Characteristics of the Anodized Film. The microstructure of the sample (as-cast Ni50:Ti50)

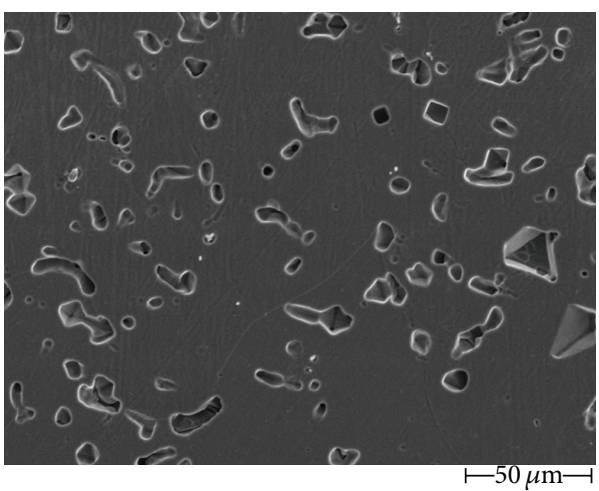

FIgURE 1: As-cast microstructure of Ni50:Ti50 sample.

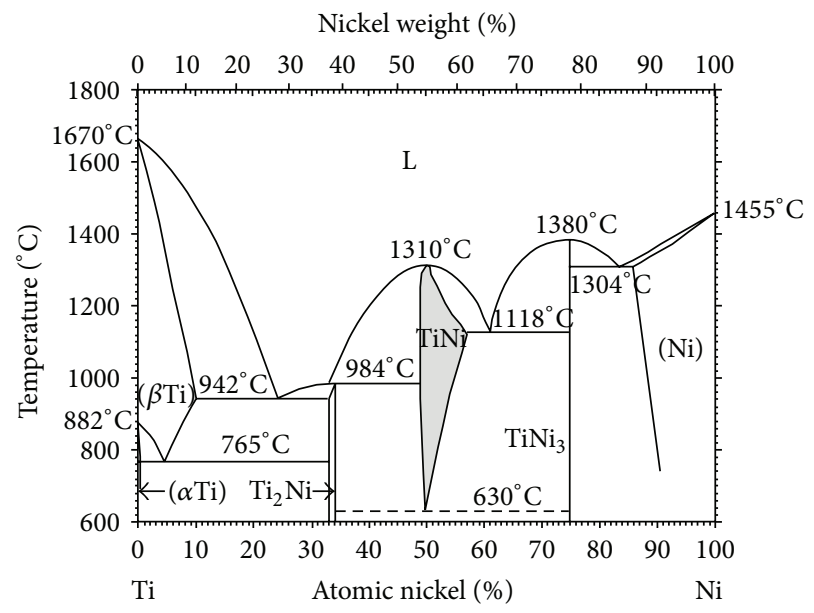

Figure 2: Ti-Ni phase diagram.

is shown in Figure 1. According to Ni:Ti phase diagram, Figure 2, the microstructure is composed of the matrix corresponding to the intermetallic phase $\mathrm{TiNi}$, and it contains few particles frequently present in the sample which is $\mathrm{Ti}_{2} \mathrm{Ni}$. After anodization, the surface microstructure was changed to semiporous structure. The surface microstructure of the as-anodized samples and the corresponding cross section are shown in Figures 3(a) and 3(b). The as-anodized samples obtained a white color, which didn't change apparently after subsequent hydrothermal treatment. According to Karambakhsh et al. [10], the color saturation of the anodized layer (chromaticity) in sulfuric acid solution reaches its maximum value (white color) when the applied voltage is equal to $10 \mathrm{v}$. In the current case, the solution is different but the same color was obtained due to the similar used voltage. A well-defined anodized layer containing semiporous structure, Figure 3(a), with approximately $1 \mu$ size was obtained in this sample. This porous structure is typical for fixation of bone implants [11].

The cross section of the anodized sample showing the thin film obtained by anodization is presented in Figure 3(c). It is clear that an anodized layer in order of $2 \mu$ was obtained. In this micrograph, some cracks (denoted by white arrow) can be seen in the formed film. This can be attributed 


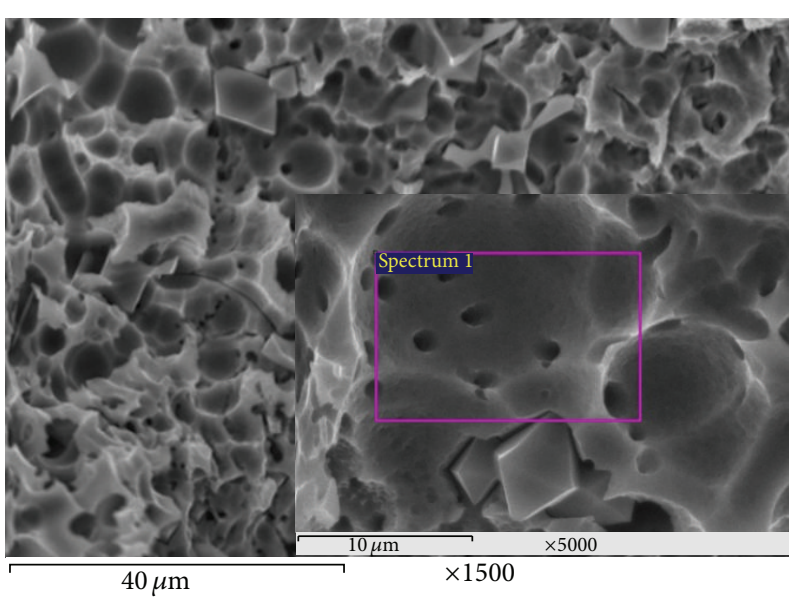

(a)

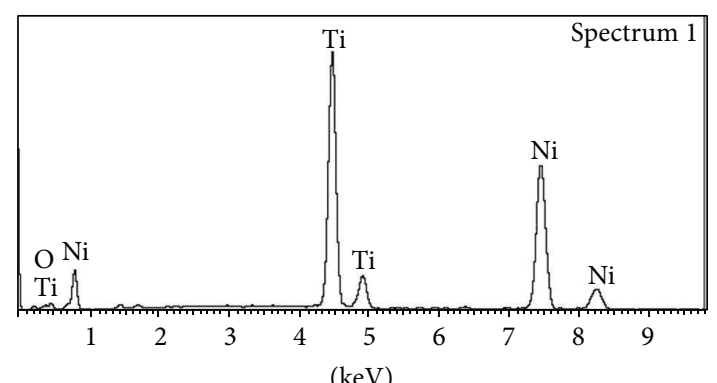

Full scale 5874 cts cursor: 9.800 (32 cts)

\begin{tabular}{|c|c|c|c|c|c|}
\hline Element & App & Intensity & Weight (\%) & Weight (\%) & Atomic (\%) \\
\hline & Conc. & Corrn. & & Sigma & \\
\hline O K & 58.17 & 0.2787 & 11.19 & 1.27 & 29.60 \\
\hline Ti K & 684.70 & 0.9338 & 39.33 & 0.63 & 34.74 \\
\hline Ni K & 838.52 & 0.9090 & 49.48 & 0.77 & 35.66 \\
\hline Totals & & & 100.00 & & \\
\hline
\end{tabular}

(b)

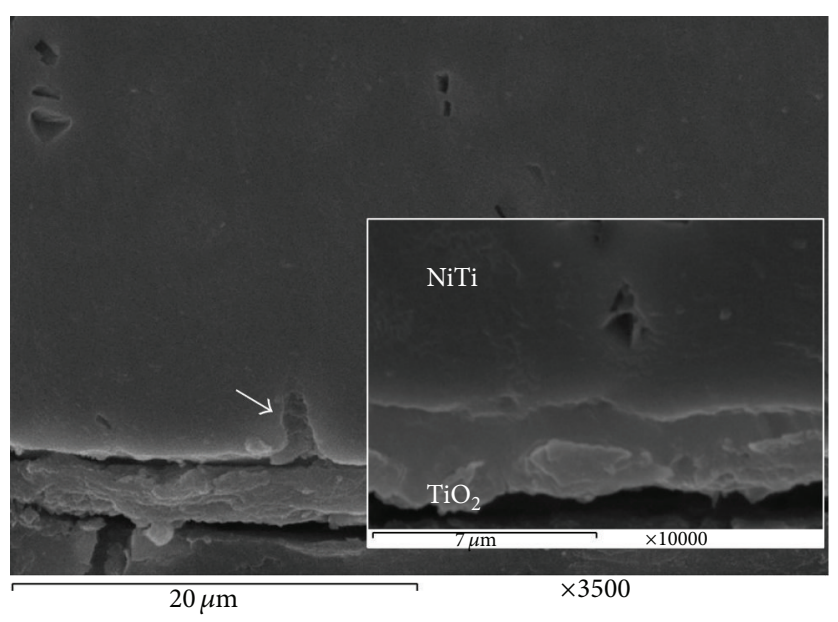

(c)

FIGURE 3: (a) SEM micrograph of the surface of $10 \mathrm{~V}-1 \mathrm{hr}$ anodized samples; (b) EDS analysis and (c) cross section showing the anodized layer.

to the formation of pathways for oxygen evolution during anodization or shrinkage of the anodization products during dry-up in air after removal from the electrolyte $[12,13]$.

\subsection{Hydrothermal Treatment of the Anodized-As-Cast Sam-} ple. In order to reveal the oxide layer, the hydrothermal treatment was performed for the as-cast sample after being anodized. Figures $4(\mathrm{a})-4(\mathrm{~d})$ present the surface topography and magnified micrographs of the anodized sample after treatment and the corresponding XRD pattern. Comparing the surface morphology presented in Figures 4(a)-4(d) to that of as-anodized sample before treatment shown in Figure 3(a), obvious differences in the nature of the anodized layer can be observed. The pores relatively increased in size and some of them formed smaller pores inside, as denoted by white arrows Figure 4(c). This could be attributed to the excessive corrosion of $\mathrm{TiO}_{2}$ during the hydrothermal treatment. Moreover, a new white phase appeared on the pore edges, represented by white arrows in Figure 4(b).

The XRD patterns of the anodization products on the samples after $18 \mathrm{~h}$ of hydrothermal treatment are, respectively, shown in Figure 4(d). Before hydrothermal treatment, the XRD pattern showed only one prominent peak between angles $20^{\circ}$ and $60^{\circ}$. This peak and all the other diffraction lines were assigned to NiTi substrate itself. The prominent 110 peak in the presented pattern belongs to the austenite phase. However, the anodized layer was visually observed as white color representing the maximum saturation of the anodized layer as discussed earlier. This means the deposited film is amorphous which is in agreement with previous pieces of work $[14,15]$.

After hydrothermal treatment, $\mathrm{NiTi}_{2}$ phase occurred at an angle of $42.28^{\circ}$. Since this phase was absent in the pattern of the untreated samples, thus it follows the detected $\mathrm{NiTi}_{2}$ 


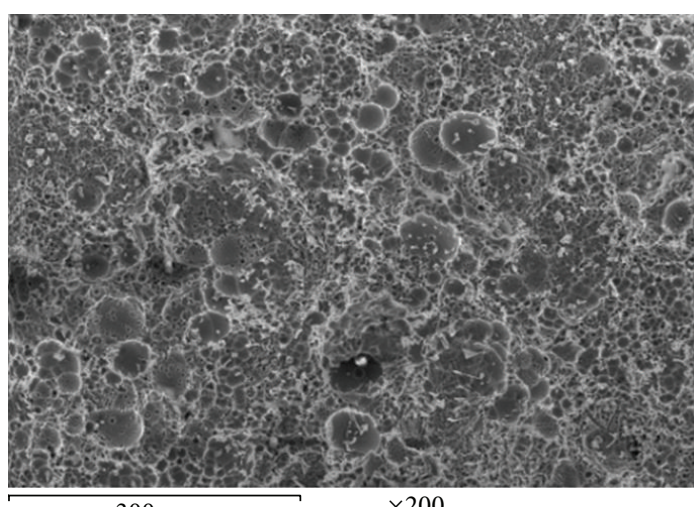

$300 \mu \mathrm{m}$

$\times 200$

(a)

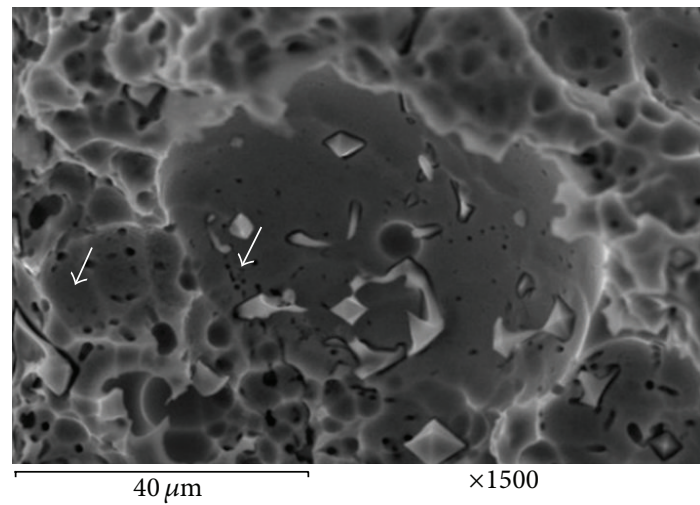

(c)

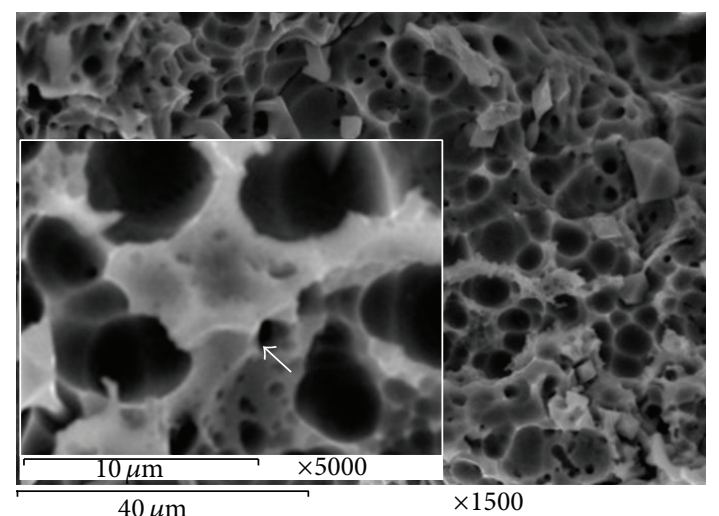

(b)

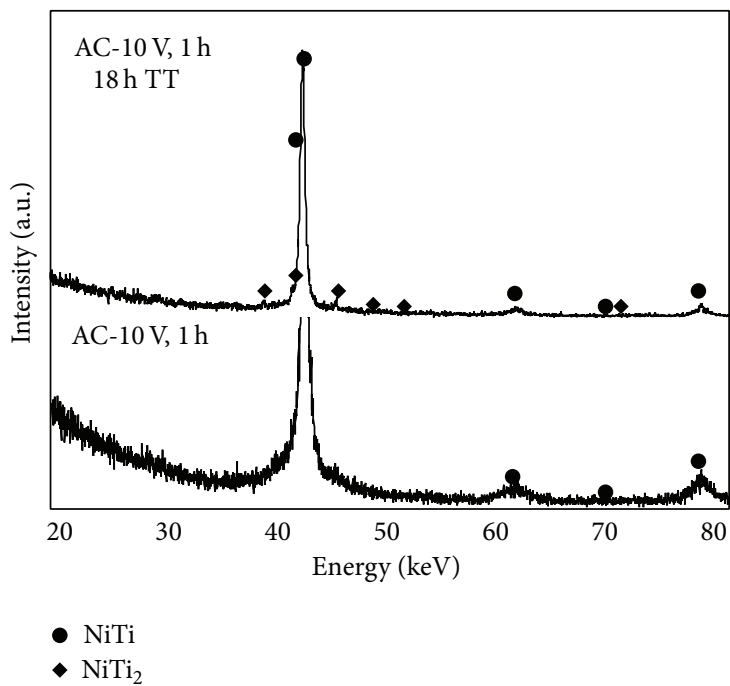

(d)

FIGURE 4: As-cast-anodized-18 h hydrothermal treatment: (a) surface topography, (b and c) magnified micrograph, and (d) the XRD pattern of the hydrothermally treated AC sample.

phase that is present in the modified surface of the treated samples rather than in the substrate. This phase is the white phase denoted by arrow in Figure 4(b). However, we still couldn't observe $\mathrm{TiO}_{2}$ because we still have amorphous structure.

The formation of $\mathrm{TiO}_{2}$ tubes and changing their diameter are a complex process that involves physical, chemical, electrochemical, and many other factors. Xue et al. [16] divided this process into four stages: (1) formation of a dense barrier oxide layer under the strong electric field $\left(\mathrm{Ti}+2 \mathrm{H}_{2} \mathrm{O} \rightarrow\right.$ $\mathrm{TiO}_{2}+4 \mathrm{H}^{+}$), (2) chemical dissolution of $\mathrm{TiO}_{2}$ to form cylindrical pores due to F-ions from electrolyte $\left(\mathrm{TiO}_{2}+4 \mathrm{H}^{+}+\right.$ $6 \mathrm{~F}^{-} \rightarrow \mathrm{TiF}_{6}{ }^{-2}+2 \mathrm{H}_{2} \mathrm{O}$ ), (3) dissolution of the porous layer resulting in final tube structure with extension of oxidation time, and (4) excessive corrosion of $\mathrm{TiO}_{2}$ tubes to form wires. These variables, voltage, duration, $\mathrm{pH}$, and ion concentration, are four types of forcing functions for the formation of wires and tubes in the anodization process. Therefore, measuring these parameters and their effectiveness on the anodized structure is suggested for future work.
Concluding, the above process can be mainly ascribed to the dissolution of $\mathrm{Ti}$ leading to decreasing $\mathrm{pH}$ value and then F-that plays an important role in the dissolution of $\mathrm{TiO}_{2}$ layer. So the formation of wires or tubes is affected not only by voltage and duration but also by $\mathrm{pH}$ and ion concentration.

\subsection{Characteristics of the Anodized Layer after Isothermal} Holding. In the previous section, the hydrothermal treatment showed some influence on the nature of anodized layer. However, the $\mathrm{TiO}_{2}$ couldn't be clearly detected by XRD which means that most of the layer is still in its amorphous state. Therefore, the samples were further heated at $2^{\circ} \mathrm{C} / \mathrm{min}$ to $450^{\circ} \mathrm{C}$ and then hold for 3 hours followed by furnace cooling. The XRD of isothermally treated samples is shown in Figure 5. The tetragonal Rutile $\mathrm{TiO}_{2}$ could be obtained along with hexagonal $\mathrm{Ni}_{3} \mathrm{Ti}$ phase. This indicates the transformation of the anodized layer from the amorphous to crystalline structure after the hydrothermal treatment.

It was reported by Tian et al. [17] that $\mathrm{Ni}_{3} \mathrm{Ti}$ layer forms due to $\mathrm{Ni}$ atoms diffusion from the free surface and their 


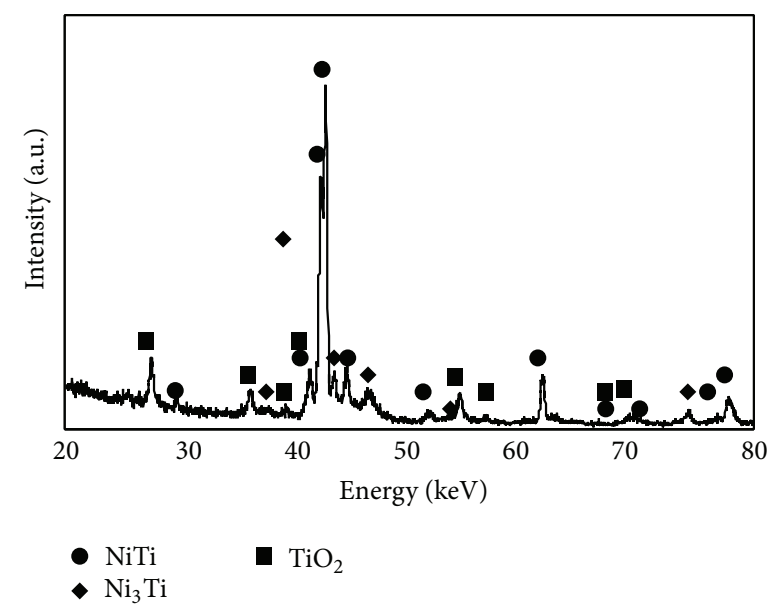

FIGURE 5: XRD pattern of the hydrothermally treated samples after $3 \mathrm{~h}$ of isothermal holding.

accumulation in the region with the lowest oxidation state that is close to metal-oxide interface. Since $\mathrm{Ni}_{3} \mathrm{Ti}$ appears as a line phase in the $\mathrm{Ni}$-Ti phase diagram, the amount of $\mathrm{Ni}$ in the intermetallic $\mathrm{Ni}_{3} \mathrm{Ti}$ layer becomes saturated upon formation of this layer. If more $\mathrm{Ni}$ content was present, $\mathrm{Ni}$ metallic particles may be formed. The absence of free $\mathrm{Ni}$ in the XRD pattern is a good indication of the success of the anodized layer to suppress Ni release to the surface. This result implies that by controlling the thickness and the oxidation state of the oxide layer, Ni release can be feasibly prevented.

3.4. Anodization and Surface Hardness. Since hardness is an essential property to consider in biomaterials applications, we found that it is necessary to evaluate hardness after surface anodization and compare it to the bare NiTi area of the ascast sample. The hardness of the anodized thin film shown in Figure 3(c) was measured as $500 \mathrm{HV}$ while that of the bare NiTi was $200 \mathrm{HV}$. This means, the hardness of the ascast sample was more than the double due to anodization. It is concluded that the deposition of gradient films could effectively improve the surface hardness of the current $\mathrm{NiTi}$ samples.

3.5. Corrosion Behavior of Cast Ni50Ti50 Alloy. The as-cast samples were corrosion tested in a Hank's biological solution. Figures 6(a) and 6(b) show the SEM micrograph and the corresponding EDS analysis of the sample after corrosion testing. The corrosion products were found frequently and were characterized by the presence of $\mathrm{Na}$ and $\mathrm{Cl}$. The electrochemical properties were obtained from the polarization curve. The electrochemical properties obtained from the Tafel curve were $I_{\text {corr }}, \mathrm{OCP}$, corrosion rate of $9.14 E-7 \mathrm{~A} \mathrm{~cm}^{-2}$, $-182 \mathrm{mV}$, and $\mathrm{mm} /$ year, respectively. Corrosion testing of the as-anodized sample showed an excellent resistance to corrosion, thus the Tafel curves appeared as vertical lines. This means that the corrosion resistance of NiTi in Hank's solution has been improved by the anodizing introduced in this study.

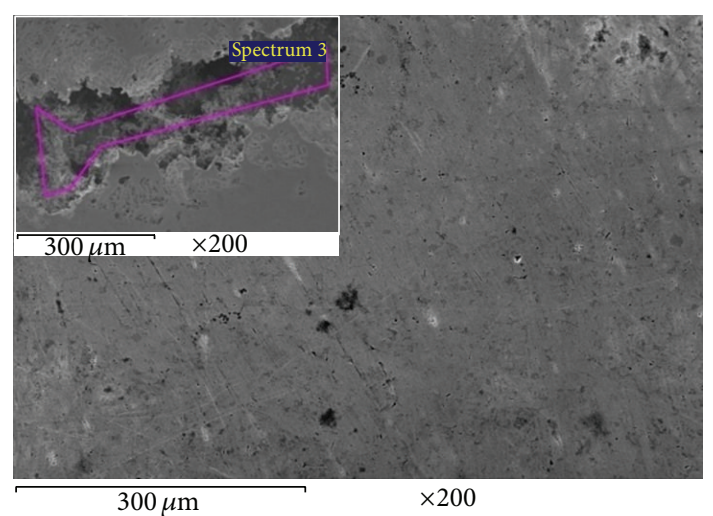

(a)

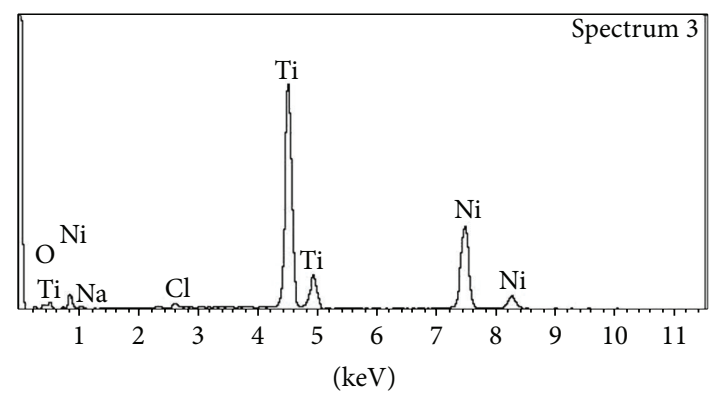

Full scale 3372 cts cursor: 11.509 (12 cts)

(b)

FIGURE 6: (a) SEM micrograph of the corroded/as-cast sample and (b) EDS analysis of the corrosion product.

\section{Conclusions}

In the current study, characteristics of anodized layer in Ni50Ti50 shape memory alloy were investigated and the following observations were concluded:

(i) the oxide film observed after isothermal holding was characterized by the absence of free $\mathrm{Ni}$ atoms/particles which is a typical requirement in terms of biocompatibility;

(ii) the anodized layer exhibited increased surface hardness and excellent corrosion resistance in contrast to untreated samples. This is also an advantage when this alloy is used as biomaterial for some specific implant which requires higher hardness and excellent corrosion resistance in the body fluid.

\section{Conflict of Interests}

The authors declare that there is no conflict of interests regarding the publication of this paper.

\section{Acknowledgment}

The authors would like to thank the laboratory of corrosion and surface protection at Central Metallurgical Research and 
Development Institute, Egypt for performing the anodization treatments.

\section{References}

[1] N. K. Simha, "Fundamental theories and mechanisms of failure," in Comprehensive Structural Integrity, I. Milne, R. O. Ritchie, and B. Karihaloo, Eds., vol. 2, pp. 573-606, Elsevier Science, 2003.

[2] Y. Zheng, L. Cui, and J. Schrooten, "Temperature memory effect of a nickel-titanium shape memory alloy," Applied Physics Letters, vol. 84, no. 1, pp. 31-34, 2004.

[3] N. Bayat, S. Sanjabi, and Z. H. Barber, "Improvement of corrosion resistance of NiTi sputtered thin films by anodization," Applied Surface Science, vol. 257, no. 20, pp. 8493-8499, 2011.

[4] F. T. Cheng, P. Shi, G. K. H. Pang, M. H. Wong, and H. C. Man, "Microstructural characterization of oxide film formed on NiTi by anodization in acetic acid," Journal of Alloys and Compounds, vol. 438, no. 1-2, pp. 238-242, 2007.

[5] K. K. Das, S. N. Das, and S. A. Dhundasi, "Nickel, its adverse health effects \& oxidative stress," Indian Journal of Medical Research, vol. 128, no. 4, pp. 412-425, 2008.

[6] G. S. Firstov, R. G. Vitchev, H. Kumar, B. Blanpain, and J. Van Humbeeck, "Surface oxidation of NiTi shape memory alloy," Biomaterials, vol. 23, no. 24, pp. 4863-4871, 2002.

[7] N. Shevchenko, M.-T. Pham, and M. F. Maitz, "Studies of surface modified NiTi alloy," Applied Surface Science, vol. 235, no. 1-2, pp. 126-131, 2004.

[8] A. K. Sharma, "Anodizing titanium for space applications," Thin Solid Films, vol. 208, no. 1, pp. 48-54, 1992.

[9] H. Habazaki, M. Uozumi, H. Konno, K. Shimizu, P. Skeldon, and G. E. Thompson, "Crystallization of anodic titania on titanium and its alloys," Corrosion Science, vol. 45, no. 9, pp. 2063-2073, 2003.

[10] A. Karambakhsh, A. Afshar, S. Ghahramani, and P. Malekinejad, "Pure commercial titanium color anodizing and corrosion resistance," Journal of Materials Engineering and Performance, vol. 20, no. 9, pp. 1690-1696, 2011.

[11] S. J. Simske and R. Sachdeva, "Cranial bone apposition and ingrowth in a porous nickel-titanium implant," Journal of Biomedical Materials Research, vol. 29, no. 4, pp. 527-533, 1995.

[12] J. Ryhänen, E. Niemi, W. Serlo et al., "Biocompatibility of nickeltitanium shape memory metal and its corrosion behavior in human cell cultures," Journal of Biomedical Materials Research, vol. 35, pp. 451-457, 1997.

[13] J. Kawakita, M. Stratmann, and A. W. Hassel, "High voltage pulse anodization of a NiTi shape memory alloy," Journal of the Electrochemical Society, vol. 154, no. 6, pp. C294-C298, 2007.

[14] M. H. Wong, F. T. Cheng, and H. C. Man, "Comparison of corrosion resistance and apatite-forming ability of NiTi treated by different low-temperature methods," Journal of Alloys and Compounds, vol. 466, no. 1-2, pp. L5-L10, 2008.

[15] A. Balyanov, J. Kutnyakova, N. A. Amirkhanova et al., "Corrosion resistance of ultra fine-grained Ti," Scripta Materialia, vol. 51, no. 3, pp. 225-229, 2004.

[16] C. Xue, F. Zhang, S. Chen, Y. Yin, and C. Lin, “Tailoring the surface morphology of $\mathrm{TiO}_{2}$ nanotube arrays connected with nanowires by anodization," Materials Science in Semiconductor Processing, vol. 14, no. 2, pp. 157-163, 2011.

[17] H. Tian, D. Schryvers, D. Liu, Q. Jiang, and J. Van Humbeeck, "Stability of Ni in nitinol oxide surfaces," Acta Biomaterialia, vol. 7, no. 2, pp. 892-899, 2011. 

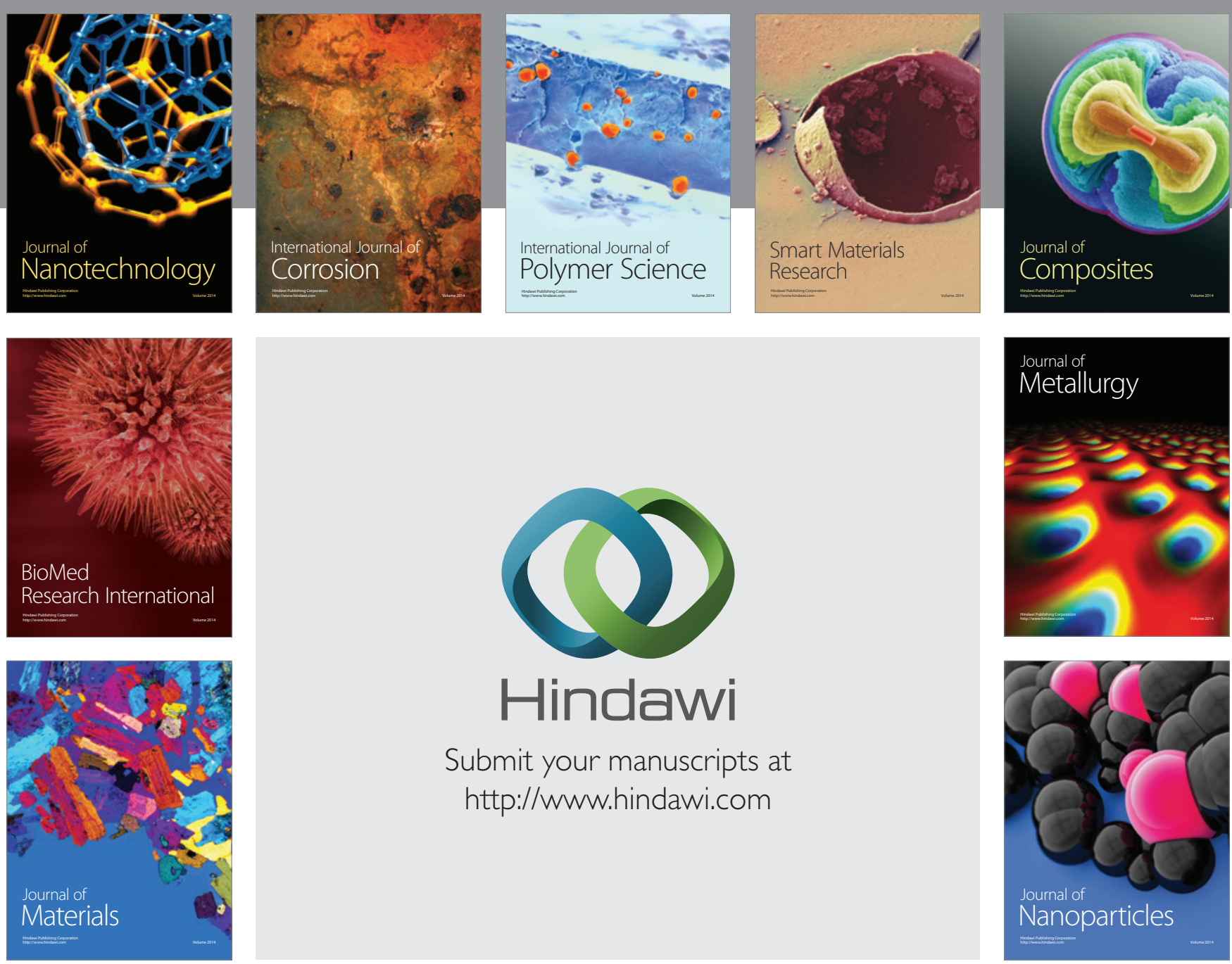

Submit your manuscripts at http://www.hindawi.com
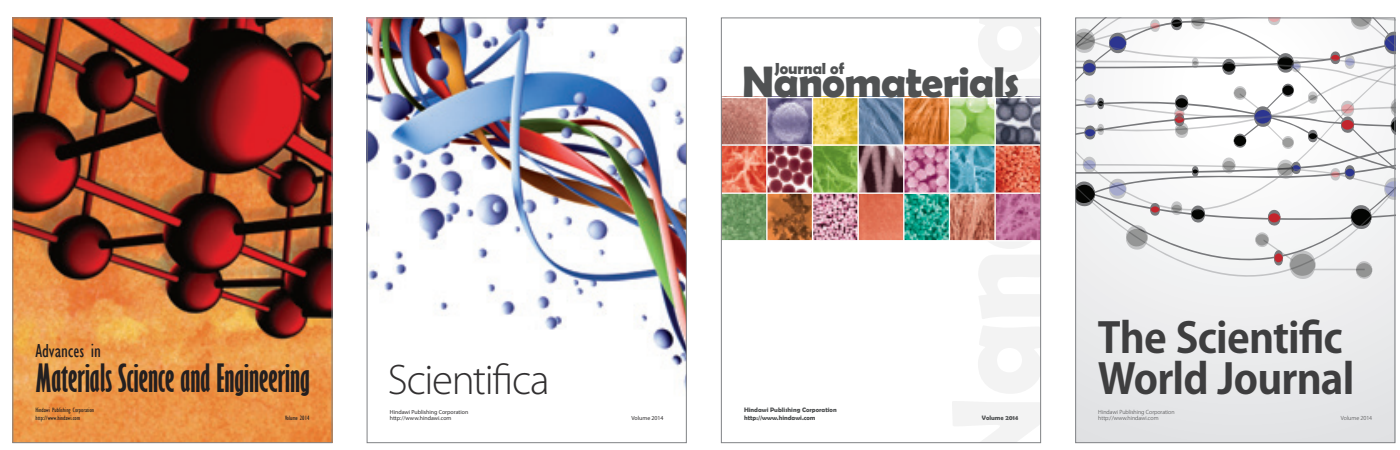

\section{The Scientific World Journal}
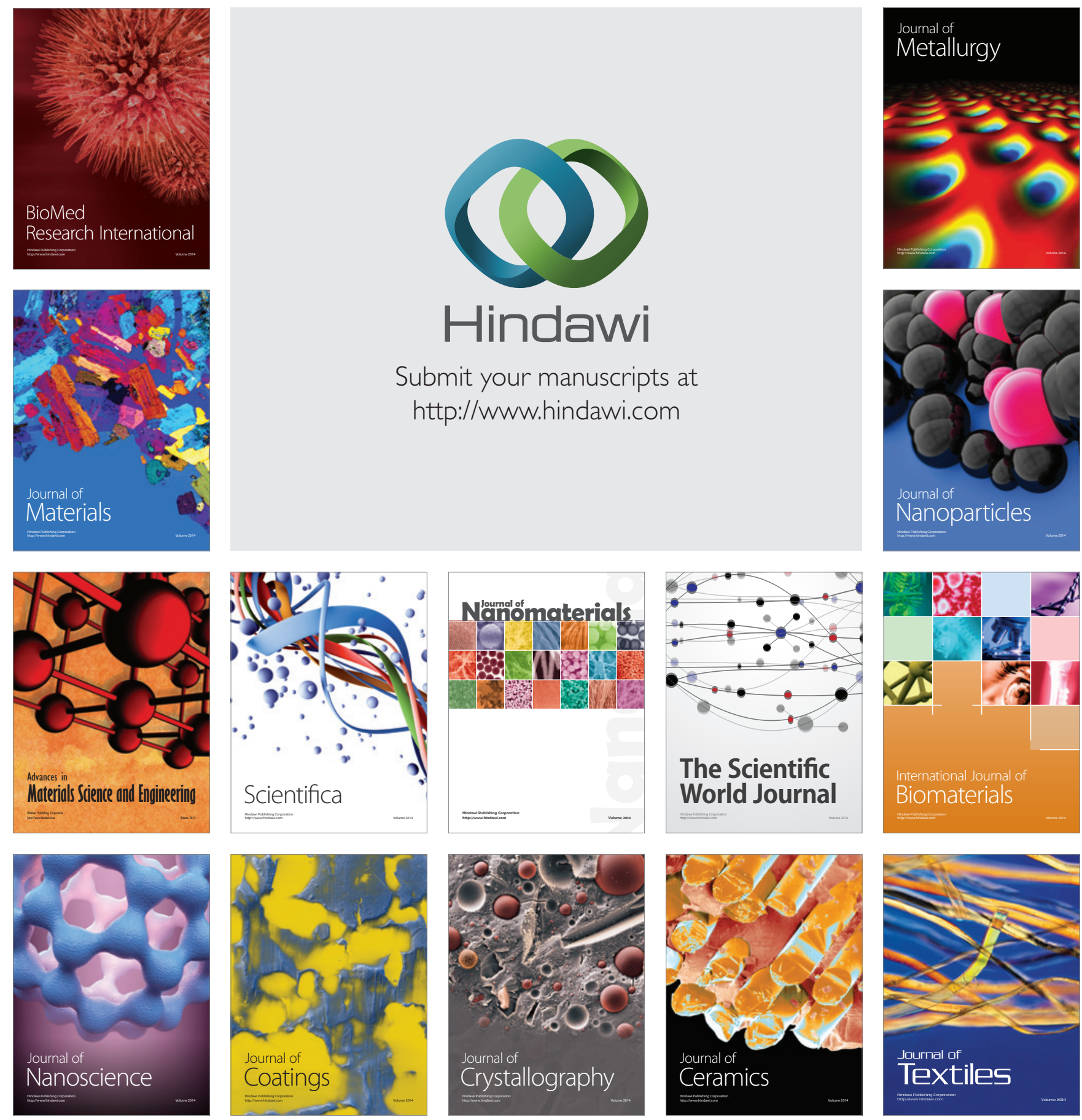